\title{
Molecular characterization of Neospora caninum MAG1, a dense granule protein secreted into the parasitophorous vacuole, and associated with the cyst wall and the cyst matrix
}

\author{
CHRISTOPHE GUIONAUD ${ }^{1}$, ANDREW HEMPHILL ${ }^{2 *}$, MEIKE MEVISSEN ${ }^{1}$ \\ and FERIAL ALAEDDINE ${ }^{1 *}$ \\ ${ }^{1}$ Institute of Veterinary Pharmacology and Toxicology, Vetsuisse Faculty, University of Berne, Länggass-Strasse 124, \\ CH-3012 Berne, Switzerland \\ ${ }^{2}$ Institute of Parasitology, Vetsuisse Faculty, University of Berne, Länggass-Strasse 122, CH-3012 Berne, Switzerland
}

(Received 9 December 2009; revised 2 February 2010; accepted 17 February 2010; first published online 6 May 2010)

\begin{abstract}
SUMMARY
In Neospora caninum and Toxoplasma gondii, the parasitophorous vacuole (PV) is synthesized at the time of infection. During tachyzoite-to-bradyzoite stage conversion, the PV is later transformed into a tissue cyst that allows parasites to survive in their host for extended periods of time. We report on the characterization of NcMAG1, the $N$. caninum orthologue of T. gondii MAG1 (matrix antigen 1; TgMAG1). The 456 amino acid predicted NcMAG1 protein is $54 \%$ identical to TgMAG1. By immunoblotting, a rabbit antiserum raised against recombinant NcMAG1 detected a major product of $\sim 67 \mathrm{kDa}$ in extracts of $N$. caninum tachyzoite-infected Vero cells, which was stained more prominently in extracts of infected Vero cells treated to induce in vitro bradyzoite conversion. Immunofluorescence and TEM localized the protein mainly within the cyst wall and the cyst matrix. In both tachyzoites and bradyzoites, NcMAG1 was associated with the parasite dense granules. Comparison between NcMAG1 and TgMAG1 amino acid sequences revealed that the C-terminal conserved regions exhibit $66 \%$ identity, while the $\mathrm{N}$-terminal variable regions exhibit only $32 \%$ identity. Antibodies against NcMAG1-conserved region cross-reacted with the orthologuous protein in T. gondii but those against the variable region did not. This indicates that the variable region possesses unique antigenic characteristics.
\end{abstract}

Key words: Neospora caninum, cyst matrix, cyst wall, parasitophorous vacuole, matrix antigen 1 (MAG1).

\section{INTRODUCTION}

Neospora caninum is an intracellular apicomplexan parasite that is closely related to Toxoplasma gondii, and represents a major cause of abortion in cattle and neuromuscular disease in dogs worldwide (Dubey et al. 2006; Hemphill et al. 2006). Transplacental transmission is regarded as the major source of infection. The life cycle of $N$. caninum consists of 3 principal stages: (1) tachyzoites, which rapidly replicate within the parasitophorous vacuole (PV), and disseminate in the host during the acute phase, (2) bradyzoites, slowly dividing parasites, which are enclosed within a tissue cyst that develops particularly in the brain during the chronic phase of the infection (Dubey et al. 2006), and (3) oocysts which represent the product of a sexual process taking place within the intestine of the definitive hosts ( $\mathrm{dog}$ and

\footnotetext{
* Corresponding author: Institute of Veterinary Pharmacology and Toxicology, Vetsuisse Faculty, University of Berne, Länggass-Strasse 124, CH-3012 Berne, Switzerland. Tel: +413163122 41. Fax: +4131631 2630. E-mail: ferial.alaeddine@vpi.unibe.ch; E-mail: hemphill@ipa.unibe.ch
}

coyote), and upon fecal shedding, sporulate and form sporozoites (McAllister et al. 1998; Gondim et al. 2004). There is evidence that tachyzoites differentiate into bradyzoites as a reaction to the immune response occurring in immune-competent hosts (Dubey et al. 2006; Hemphill et al. 2006).

Intracellularly, all invasive stages of $N$. caninum are located within a parasitophorous vacuole (PV), separated from the host cell cytoplasm through the parasitophorous vacuole membrane (PVM). The PVM is derived from the host cell cytoplasmic membrane during host cell invasion, and subsequently undergoes important modifications. While proteins secreted by the parasite are incorporated into the PVM, those of the host cell are selectively eliminated and the $\mathrm{PV}$ becomes resistant to fusion with lysosomes (Beyer et al. 2002). The PV of $T$. gondii transforms into a tissue cyst very early after parasite penetration into brain cells, and the PVM progressively matures into a cyst wall that protects bradyzoites from the immunological and physiological responses on part of the host (Beyer et al., 2002). Intact tissue cysts containing bradyzoites of both $N$. caninum and $T$. gondii can persist in the host, usually without being harmful or causing an 
inflammatory response (Dubey et al. 1988; Innes et al. 2002).

The proteins involved in tachyzoite-bradyzoite interconversion could represent important targets for vaccination or chemotherapy in order to prevent or reduce the development of intra-cerebral cysts. Stage-specifically expressed proteins in $T$. gondii and $N$. caninum have been identified (McAllister et al. 1996; Fuchs et al. 1998; Ferguson, 2004; RiscoCastillo et al. 2007; Aguado-Martinez et al. 2009), while others are expressed in both stages, but differ in their localization (Vonlaufen et al. 2004). In this context, T. gondii MAG1 was first reported as a bradyzoite-specific antigen localized in the cyst matrix (Parmley et al. 1994). Subsequently, the protein was also detected in the parasitophorous vacuoles containing intracellular tachyzoites and in tachyzoite lysates (Ferguson and Parmley, 2002). Besides its importance as a marker for cerebral infection with $T$. gondii in AIDS patients (Contini et al. 2002; Pfrepper et al. 2005), TgMAG1 represents a potentially useful tool for the immunodiagnosis of patients with toxoplasmosis (Di Cristina et al. 2004; Pfrepper et al. 2005). In addition, TgMAG1 has been considered as a promising candidate in vaccination trials (Parmley et al. 2002; Nielsen et al. 2006). We have recently shown that intraperitoneal vaccination of mice with recombinant NcMAG1 expressed in $E$. coli confers $50 \%$ protection against experimental $N$. caninum infection in a murine acute disease model (Debache et al. 2009). In this study, we report on the molecular characterization, localization and antigenic properties of NcMAG1.

\section{MATERIALS AND METHODS}

\section{Parasite cultures}

Parasites were cultured as previously described (Barber et al. 1995; Hemphill and Gottstein, 1996). Briefly, N. caninum NC-Liverpool or $T$. gondii ME49 tachyzoites were maintained in Vero cells at $37{ }^{\circ} \mathrm{C}$ under $5 \% \mathrm{CO}_{2}$ in RPMI 1640 medium containing 10\% FCS (Gibco-Invitrogen, Carlsbad, CA, USA), 2 mu L-glutamine, $50 \mathrm{IU} / \mathrm{ml}$ penicillin, and $50 \mu \mathrm{g} / \mathrm{ml}$ streptomycin. $N$. caninum grown in keratinocytes were cultured as previously described (Vonlaufen et al. 2002).

Tachyzoite-to-bradyzoite stage conversion was performed in vitro by 10 days treatment of $\mathrm{NC}$ Liverpool-infected Vero cells with $17 \mu \mathrm{M}$ sodium nitroprusside (SNP; Sigma, St Louis, MO, USA), using a procedure adapted from Vonlaufen et al. (2004) and by 4 days treatment of $T$. gondii-infected Vero cells with $100 \mu \mathrm{M}$ SNP as previously described (Bohne et al. 1994; Weiss et al. 1998).

For purification, parasites were mechanically released from infected cells by passing through a $25 \mathrm{G}$, $5 / 8$ needle, washed in ice-cold medium, and run on
PD-10 columns (GE Healthcare, Piscataway, NJ, USA) as described by Hemphill et al. (1996).

\section{Oligonucleotides}

$N$. caninum $M A G 1$-specific primers were designed based on the ApiDots (http://www.cbil.upenn.edu/ apidots/; (Li et al. 2003, 2004)) DT.92484705 transcript. All primers were purchased from MWG (Ebersberg, Germany).

\section{$R N A$ isolation and first strand $c D N A$ synthesis}

Total RNA was isolated from $3 \times 10^{6}$ purified $N$. caninum Liverpool tachyzoites using Trizol reagent (Invitrogen, Carlsbad, CA, USA) according to the manufacturer's instructions. First strand cDNA synthesis reactions were performed for $1 \mathrm{~h}$ at $42{ }^{\circ} \mathrm{C}$ in a $20 \mu \mathrm{l}$ reaction mixture containing $2 \mu \mathrm{g}$ of total RNA, $1 \times$ first-strand buffer (Invitrogen), $0.5 \mathrm{~mm}$ of each dNTP (Endotell, Allschwil, Switzerland), $10 \mathrm{~mm}$ dithiothreitol, $20 \mathrm{U}$ of RNasin RNase inhibitor (Promega, Madison, WI, USA), $200 \mathrm{U}$ of SuperScript II reverse transcriptase (Invitrogen). Primers $(20 \mathrm{pmol})$ were either MAG1-R1, 5'-CTGTCCCTTACACCTACACT-3', for the 5'-RACE (Rapid Amplification of cDNA Ends) and to generate the recombinant NcMAG1 protein, or T-primer 3, 5'-AAGCAGTGGTATCAACGCAGAGTA$\mathrm{C}(\mathrm{T})_{30} \mathrm{VN}-3^{\prime}(\mathrm{V}=\mathrm{A}, \mathrm{C}$ or $\mathrm{G} ; \mathrm{N}=$ any nucleotide), for the 3'-RACE (Matz et al. 1999).

\section{$R A C E$ procedures}

A manual hot-start PCR (Chou et al. 1992) was used in order to reduce background amplifications in both RACE reactions.

For 5'-RACE, the first strand cDNA primed with MAG1-R1 primer was ultrafiltrated 3 times against water on a Microcon YM-100 filter unit (Millipore, Billerica, MA, USA). The cDNA in the whole retentate was dA-tailed for $20 \mathrm{~min}$ at $37^{\circ} \mathrm{C}$ in $50 \mu \mathrm{l}$ of $1 \times$ terminal deoxynucleotidyl transferase (TdT) buffer (Roche, Basel, Switzerland) using $25 \mathrm{U}$ of TdT (Roche) and $0.2 \mathrm{~mm}$ dATP (Endotell). The reaction was terminated by heating at $95{ }^{\circ} \mathrm{C}$ for $5 \mathrm{~min}$. Two rounds of amplification were performed to generate the 5 '-RACE product. The first round was carried out in a $50 \mu 1$ reaction volume containing $5 \mu \mathrm{l}(1 / 10 \mathrm{th})$ of the (dA)-tailed product, $5 \mathrm{pmol}$ of each T-primer 3 and MAG1-R2 (5'-GCATTACCAACTTCGTCCTC-3') primers, $0 \cdot 2 \mathrm{~mm}$ of each dNTP and $2.5 \mathrm{U}$ of $P f u$ DNA polymerase (Promega) in the supplied reaction buffer. Ten PCR cycles were performed with an annealing temperature of $55^{\circ} \mathrm{C}$. The second round of amplification was carried out in $50 \mu \mathrm{l}$ containing $20 \mu \mathrm{l}$ of the first step 
amplification reaction, 15 pmol of Heel-carrier (5'CTAATACGACTCACTATAGGGCAAGCAGTGGTATCAACGCAGAGT-3') and MAG1-R2 primers, $0.2 \mathrm{~mm}$ of each dNTP, and $2.5 \mathrm{U}$ of $P f u$ DNA polymerase (Promega) in the supplied reaction buffer. PCR was performed for 30 cycles with an annealing temperature of $58{ }^{\circ} \mathrm{C}$.

The $3^{\prime}$-RACE reaction was carried out in a $100 \mu \mathrm{l}$ reaction mixture containing $2 \mu \mathrm{l}(1 / 10 \mathrm{th})$ of the first strand cDNA prepared with T-primer 3, 4 pmol of Heel-carrier primer, 20 pmol of each MAG1-F (5'-TGAACAACCCTATGAACAAACAGACGC$\left.3^{\prime}\right)$, and Heel-specific (5'-CTAATACGACTCACTATAGGGC-3') primers, $0 \cdot 2 \mathrm{~mm}$ of each dNTP and $2.5 \mathrm{U}$ of $P f u$ DNA polymerase in the supplied reaction buffer. PCR was performed for 35 cycles with an annealing temperature of $55^{\circ} \mathrm{C}$.

\section{Sequencing and sequence analyses}

RACE products were cloned into pCR Blunt II TOPO (Invitrogen) and sequenced using a primer walking approach. All expression constructs were verified by sequencing of the insert. Sequencing reactions were carried out using BigDye v3.1 fluorescent dye terminators and run on an ABI PRISM 3100 Genetic Analyzer (Applied Biosystems, Foster City, CA, USA). Raw sequencing data were assembled and edited with the Staden package (Bonfield et al. 1995). Sequence data reported in this paper are available in the GenBank database under the Accession number EF580924.

Homology searches were done using BLAST (blastp) program (http://www.ncbi.nlm.nih.gov/ blast/; (Altschul et al. 1990)) and the Conserved Domain Database CD-Search (http://www.ncbi. nlm.nih.gov/Structure/cdd/wrpsb.cgi) with default settings. Proteins were aligned on the Muscle server (http://www.drive5.com/muscle/ (Edgar, 2004)), minimally edited, and formatted with GeneDoc (Nicholas et al. 1997). Residue grouping and shading was according to the MM5 reduced amino acid alphabet of Melo and Marti-Renom (2006). Potential signal peptide cleavage sites were identified with SignalP 3.0 (http://www.cbs.dtu.dk/services/ SignalP/ (Bendtsen et al. 2004)) and potential transmembrane regions were checked with the ProtScale tool on the Expasy server (http://expasy.org/tools/ protscale.html).

\section{Expression of recombinant $\mathrm{N}$. caninum $M A G 1$ proteins}

A portion of NcMAG1, thereafter referred to as recNcMAG1, encoding aa 31-394 (numbering according to the precursor) was amplified by RT-PCR using MAG1-BamHI-F (5'-GGATCCCAAAGGGTGCCTCGCTACCC-3') and MAG1-SmaI-R
(5'-CCCGGGTTATTCCTCCACTATTTCGT-

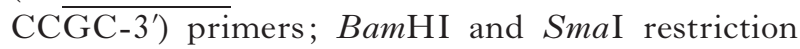
sites underlined. The PCR product was cloned into pCR blunt II TOPO (Invitrogen) and verified by sequencing. The BamHI/SmaI MAG1 insert was then subcloned into the (His) $)_{6}$-tag pQE-30 expression vector (Qiagen, Hilden, Germany), resulting in pQE-30-NcMAG1. We also expressed portions of the conserved (C) and variable (V) regions within NcMAG1 (Fig. 2). In order to monitor their expression and to facilitate their purification, the two NcMAG1 $\mathrm{C}$ and $\mathrm{V}$ regions were expressed as (His) ${ }_{6}$-GFP (green fluorescent protein) fusion proteins in E. coli. The portion of NcMAG1 central to the $\mathrm{C}$ region (aa 241-386, numbering according to the precursor) was amplified using MAG1-C-XmaIF (5'-CTGCGTCCCGGGGGACCGACGGTTTCGACTCG-3') and MAG1-C-PstI-R (5'-CTGCGTCTGCAGGGTCCCCACGAATTGTCTCG-3') primers; $X m a \mathrm{I}$ and $P s t \mathrm{I}$ restriction sites underlined. The portion of NcMAG1 central to the $\mathrm{V}$ region (aa 31-162) was amplified using MAG1-VXmaI-F (5'-CTGCGTCCCGGGCAAAGGGTGCCTCGCTACCC-3') and MAG1-V-PstI-R (5'-CTGC GTCTGCAGCGACGTGGAAAGTGGTAGCG-3' primers; $X m a \mathrm{I}$ and PstI restriction sites underlined. The $\mathrm{pQE}-30-\mathrm{NcMAG} 1$ vector was used as template for PCR amplifications. Restricted PCR products were inserted into the $X m a \mathrm{I} /$ PstI-cut pQE-GFP vector (C.G. and F.A., unpublished; sequence available upon request), resulting in pQE-GFP-MAG1-C and pQE-GFPMAG1-V.

Expression vectors were used to transform $E$. coli BL21 (Novagen-EMD Biosciences, Madison, WI) harbouring the pREP4 repressor plasmid (Qiagen). To express the recombinant proteins, 11 of $2 \times$ YT medium (per litre: $16 \mathrm{~g}$ bacto tryptone, $10 \mathrm{~g}$ bacto yeast extract, and $5 \mathrm{~g} \mathrm{NaCl}$ ), pre-warmed to $37^{\circ} \mathrm{C}$ and supplemented with carbenicillin and kanamycin (Sigma; 100 and $25 \mathrm{mg} / \mathrm{ml}$, respectively), was inoculated with $10 \mathrm{ml}$ of an overnight starter culture grown in the same medium. When cultures reached an OD of 0.5 at $\lambda=600 \mathrm{~nm}$, isopropyl $\beta$-D-1thiogalactopyranoside (Sigma) was added to $1 \mathrm{~mm}$ and expression was carried on for $3 \mathrm{~h}$ at $37^{\circ} \mathrm{C}$. Soluble recNcMAG1 and GFP-MAG1-V proteins were purified by nickel chelate chromatography on Protino Ni-IDA columns (Macherey-Nagel, Düren, Germany), as recommended by the manufacturer. Due to its extreme sensitivity to proteolysis after bacterial lysis, GFP-MAG1-C could not be purified by chromatography. It was therefore run on a large format SDS-PAGE gel after boiling over-expressing bacteria in SDS sample buffer. The whole gel was transferred onto a nitrocellulose membrane and the major band was excised and used for the purification of anti-GFP-MAG1-C antibodies. 


\section{Production and purification of antibodies}

Antisera were obtained after immunization of 2 female white New Zealand rabbits, with $150 \mu \mathrm{g}$ of recNcMAG1 antigen per injection, using a standard 10-week immunization protocol (Institut für Labortierkunde, Zurich, Switzerland). Antibodies specific to either the whole recNcMAG1, the $\mathrm{C}$ or the $\mathrm{V}$ region were affinity-purified using recNcMAG1, GFP-MAG1-C or GFP-MAG1-V bound to nitrocellulose membranes, respectively (Robinson et al. 1988).

\section{Preparation of protein extracts}

For preparation of total protein extracts from infected or uninfected Vero cells, cultures in a T-75 culture flask were washed twice with PBS (137 mM $\mathrm{NaCl}, 2.7 \mathrm{~mm} \mathrm{KCl}, 4.3 \mathrm{~mm} \mathrm{Na}_{2} \mathrm{HPO}_{4}, 1.47 \mathrm{~mm}$ $\left.\mathrm{KH}_{2} \mathrm{PO}_{4}, \mathrm{pH} 7 \cdot 4\right)$ and proteins were extracted with $1 \mathrm{ml}$ of ice-cold RIPA buffer (Pierce-Thermo Fisher Scientific, Waltham, MA, USA) supplemented with $10 \mu \mathrm{l} / \mathrm{ml}$ Halt protease inhibitor cocktail (PierceThermo Fisher Scientific). Protein extracts were sonicated, clarified by centrifugation, and the protein concentration in the supernatant was measured using the DC Protein Assay Kit (Bio-Rad, Hercules, CA, USA). For SDS-PAGE, samples of protein extracts from infected cultures were adjusted to contain the required parasite number using data obtained by quantitative real-time PCR.

Protein extracts from free parasites were prepared using $100 \mu \mathrm{l}$ of RIPA buffer per $5 \times 10^{6}$ purified parasites.

\section{Quantitation of parasites}

To determine the number of parasites in infected Vero cells, a quantitative real-time PCR (LightCycler, Roche Diagnostics, Basel, Switzerland) was used. DNA was purified from Neospora- or Toxoplasma-infected cells using the High Pure PCR Purification kit (Roche Diagnostics) according to the manufacturer's recommendations. DNA concentrations were measured by Hoechst 33258 (Sigma) fluorimetry (Ausubel et al. 1997) on a Synergy HT plate reader (Biotek Instruments, Winooski, VT, USA). Experimental procedures described by Müller et al. (2002) for Neospora and Reischl et al. (2003) for Toxoplasma were followed, using $200 \mathrm{ng}$ DNA per sample. Free parasites were directly quantified by counting using a Neubauer chamber.

\section{SDS-polyacrylamide gel electrophoresis (SDS-PAGE) and Western blot}

Protein samples were mixed with reducing, denaturing sample buffer, boiled for $5 \mathrm{~min}$ and protein separation was conducted by SDS-PAGE. Proteins were transferred onto PVDF membranes (Bio-Rad) for $1 \mathrm{~h}$ at $100 \mathrm{~V}$ using a wet transfer apparatus (BioRad). Membranes were blocked by incubation in a blocking buffer containing $5 \%$ non-fat milk in TBST (20 my Tris, $150 \mathrm{~mm} \mathrm{NaCl,} \mathrm{0 \cdot 1 \%} \mathrm{(v/v)} \mathrm{Tween} \mathrm{20)}$ and then incubated for $2 \mathrm{~h}$ at room temperature or overnight at $4{ }^{\circ} \mathrm{C}$ with affinity-purified antiNcMAG1 antibodies at a dilution of $1: 3000$. Antibodies against the NcMAG1-conserved region and against the NcMAG1-variable region were applied at a dilution of $1: 400$. Detection was performed with a donkey anti-rabbit alkaline phosphataseconjugated secondary antibody (Pierce-Thermo Fisher Scientific) at a dilution of 1:10 000 and NBT / BCIP (nitro blue tetrazolium/bromochloroindolyl phosphate; Sigma) (Ausubel et al. 1997).

\section{Immunofluorescence (IF) analysis}

IF staining was performed on purified parasites or on parasite-infected Vero cells grown on poly-L lysinecoated glass cover-slips. For intracellular bradyzoites, cover-slips were seeded $\left(10^{5}\right.$ infected cells per well) on the sixth day following addition of SNP to the culture medium and the treatment carried on until day 9 post-infection. Purified parasites were fixed using 4\% paraformaldehyde in PBS (20 min at RT). Cover-slips were rinsed 3 times in PBS, immersed into pre-cooled $\left(-20^{\circ} \mathrm{C}\right)$ methanol/ acetone $(\mathrm{v}: \mathrm{v})$, and incubated at $-20{ }^{\circ} \mathrm{C}$ for $30 \mathrm{~min}$. The cover-slips were washed 3 times with PBS, 5 min each, and incubated in blocking buffer (PBS/ $3 \% \mathrm{BSA}$ ) for $2 \mathrm{~h}$. The following primary antibodies, diluted in PBS/0.3\% BSA, were applied: (a) affinitypurified polyclonal rabbit anti-NcMAG1 antibody at a $1: 2500$ dilution, (b) rabbit anti $N$. caninum antiserum (Hemphill et al. 1996) at a 1:2500 dilution, (c) $\mathrm{CC} 2$, a rat $\mathrm{mAb}$ reacting with a $T$. gondii cyst wall antigen (Gross et al. 1995), diluted at 1:300, and (d) rabbit anti-BAG1 polyclonal antibody, directed against a bradyzoite-specific antigen (McAllister et al. 1996), diluted at $1: 300$. Affinity-purified antibodies against NcMAG1-conserved and NcMAG1variable regions were used at 1:200 to assess their cross-reactivity on $T$. gondii.

Incubations with primary antibodies were performed for $1 \mathrm{~h}$, followed by 3 washes in PBS for $5 \mathrm{~min}$ each. Cells were then incubated for $45 \mathrm{~min}$ with the appropriate Alexa Fluor (AF)-labelled secondary antibodies (Invitrogen) at a dilution of $1: 3000$ (AF-488-, AF-546) or 1:300 (AF-350) in PBS $/ 0 \cdot 3 \%$ BSA. For multiple detection, antibodies were applied sequentially, without a given order. Finally, the preparations were washed in PBS 3 times for $5 \mathrm{~min}$ each. Cover-slips with infected cells were incubated for $2 \mathrm{~min}$ in PBS containing DAPI at $1 \mu \mathrm{g} /$ $\mathrm{ml}$ to stain nuclei, rinsed briefly in PBS, and mounted in ProLong Gold antifade reagent (Invitrogen). 
Images were acquired on an Axioskop 2 microscope equipped with an AxioCam CCD camera (Carl Zeiss, Oberkochen, Germany) or on a Nikon Eclipse 80i microscope (Kanagawa, Japan) equipped with a QImaging cooled CCD camera (Retiga 2000R Fast 1394; Surrey, BC, Canada). Images were processed with ImageJ 1.38 software (http://rsb.info.nih.gov/ ij/; (Abramoff et al. 2004)).

\section{Immunogold-labelling and transmission electron microscopy $(T E M)$}

LR-White embedding and on-section labelling of $N$. caninum cultures were performed essentially as previously described (Hemphill and Croft, 1997; Vonlaufen et al. 2002, 2004). Sections were loaded onto formvar-carbon coated grids and non-specific binding sites were blocked for $2 \mathrm{~h}$ in PBS/1\% BSA. They were then incubated in affinity-purified anti-NcMAG1 antibodies, diluted $1: 100$ in PBS/ $0 \cdot 1 \%$ BSA for $1 \mathrm{~h}$. After washing in 5 changes of PBS ( 2 min each), the goat anti-rabbit antibody conjugated to $10 \mathrm{~nm}$ diameter gold particles (Amersham) was applied at a dilution of $1: 5$ in PBS/ $0 \cdot 1 \%$ BSA. After extensive washing in PBS, grids were air-dried and stained with lead citrate and uranyl acetate. Specimens were viewed on a Philips 400 TEM (Philips Electronics, Eindhoven, The Netherlands) operating at $80 \mathrm{kV}$.

RESULTS

\section{Cloning and analysis of a $c D N A$ encoding} Neospora caninum $M A G 1$

A sequence homology search against $N$. caninum expressed sequence tags (ESTs) in the ApiDots database (Li et al. 2003, 2004) using $T$. gondii MAG1 cDNA (Parmley et al. 1994) resulted in a single hit, a 2886 NT assembly of 21 ESTs: DT.92484705. This consensus sequence possesses an open reading frame $(\mathrm{ORF})$ potentially encoding a protein sharing over $50 \%$ identity with $T$. gondii MAG1. To confirm the DT.92484705 data, we amplified NcMAG1 cDNA by RACE, using a first strand cDNA prepared from $N$. caninum Liverpool tachyzoites as a template. The 5'-RACE reaction produced a single amplicon of $\sim 1.5 \mathrm{~kb}$, consistent with the sequence of the five 5'-RACE clones that we analysed. On the contrary, agarose gel electrophoresis of $3^{\prime}$-RACE products revealed a more complex banding pattern, with discrete fragments ranging from 0.6 to over $1.5 \mathrm{~kb}$ (data not shown). After bulk cloning and sequencing of twelve 3 -RACE products, we found that differences between clones were limited to their 3 '-end, immediately preceding the poly(A) tail, suggesting an alternative polyadenylation site usage.
The unique 5 '- and the longest 3 '-RACE products, overlapping by $345 \mathrm{NT}$, were used to build a 2288 NT NcMAG1 cDNA sequence (GenBank Accession no. EF580924; Fig 1). The consensus cDNA possesses a 1371 nucleotide ORF (including the TGA stop codon), potentially encoding a 456 amino acid protein identical to that predicted to be encoded by the DT. 92484705 transcript. The putative ATG initiation codon is part of a sequence (AGCACAATGG) matching 8 positions of the previously described $T$. gondii translation initiation consensus sequence (gNCAAaATGg) (Seeber, 1997). An additional, out-of-frame, ATG triplet was found closer to the NcMAG1 cDNA 5'-end (NT 52-54); however, in a context apparently less favourable for translation initiation.

The predicted $5^{\prime}$-UTR is 128 NT long, 76 NT shorter than in the ApiDots transcript. The twelve 3'-RACE clones sequenced had a 3'-U'TR ranging from 304 to 789 N'T and a poly(A) tail, but electrophoretic analysis of $3^{\prime}$-RACE products suggested that polyadenylation of the NcMAG1 transcript could occur even further downstream, consistent with the longer 3'-UTR present on the DT.92484705 transcript. We did not observe any consensus eukaryotic polyadenylation signal (AATAAA) downstream of the coding sequence. However, performing a less stringent search, 6 out of the 12 analysed transcripts appeared to be terminated in close vicinity (within the generally accepted 10-30 NT window) to upstream sequences differing at most by 1 mismatch from the consensus AATAAA hexamer. An imperfect 84/90 NT direct repeat was identified (NT 1934-2017 and 2019-2108) in the 3'-UTR (Fig. 1).

The predicted NcMAG1 precursor is $54 \%$ identical to TgMAG1 (Fig. 2) but does not share significant similarity to any other protein in GenBank nor in the Conserved Domain Database (CDD v2.17, October 2009). A typical signal peptide with a predicted signal peptidase cleavage site between $\mathrm{Gly}_{30}$ and $\mathrm{Gln}_{31}$ was identified by SignalP 3.0 with the hidden Markov models and the neural networks prediction methods (Bendtsen et al. 2004). The position of the predicted cleavage site was conserved in TgMAG1, but only with the hidden Markov models method (Fig. 2). The predicted MWs of NcMAG1 are 52.9 and $50.5 \mathrm{kDa}$, for the precursor and the mature protein, respectively.

We did not identify a hydrophobic region that could represent an internal transmembrane domain. The predicted NcMAG1 and TgMAG1 mature proteins share an overall $53 \%$ identity but sequence conservation is not homogeneously distributed along the proteins. The C-terminal region (aa189-456) is much more conserved than the $\mathrm{N}$-terminal region (aa 31-188), with $66 \%$ and $32 \%$ sequence identity, respectively (Fig. 2). 
1 aacagttgaa caatcgtttc gtgactctct ggtggtctgt ctgtgtacta gatgtactct ttccoagce getcgaggaa catacgtgaa gcacggtggt $\begin{array}{lllllllllllllllllllllllll}M & \text { A } & \text { F } & \text { G } & \text { R } & \text { G } & \text { K } & \text { R } & \text { G } & \text { L } & \text { H } & \text { A } & \text { A } & \text { V } & \text { I } & \text { L } & \text { G } & \text { F } & \text { F } & \text { V } & \text { L } & \text { L } & \text { A } & \text { T }\end{array}$ 101 acttcctgta gcaaacata gcagcacaAT GGCGTTCGGA CGAGGCAAGA GGGGACTGCA CGCTGCAGTC ATCTTAGGCT TCTTTGTCCT CCTCGCCACA

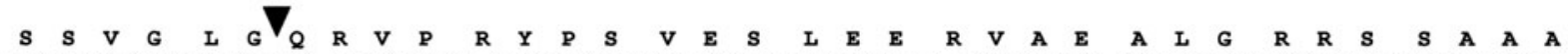
201 TCATCTGTAG GATTGGGCCA AAGGGTGCCT CGCTACCCAA GTGTGGAGTC ACTCGAAGAA AGAGTTGCCG AGGCTCTAGG GCGCCGTAGC TCCGCAGCGG $\begin{array}{lllllllllllllllllllllllllllllllllll}\mathbf{S} & \mathbf{T} & \mathbf{L} & \mathbf{P} & \mathbf{G} & \mathbf{S} & \mathbf{D} & \mathbf{T} & \mathbf{N} & \mathbf{M} & \mathbf{I} & \mathbf{S} & \mathbf{D} & \mathbf{G} & \mathbf{R} & \mathbf{A} & \mathbf{G} & \mathbf{R} & \mathbf{D} & \mathbf{E} & \mathbf{P} & \mathbf{T} & \mathbf{A} & \mathbf{S} & \mathbf{P} & \mathbf{E} & \mathbf{H} & \mathbf{H} & \mathbf{S} & \mathbf{V} & \mathbf{D} & \mathbf{A} & \mathbf{P}\end{array}$ 301 CCAGTACTCT TCCAGGGAGT GACACGAACA TGATATCAGA TGGTCGCGCA GGCAGGGATG AACCAACAGC GAGCCCAGAG CATCATTCCG TGGACGCTCC

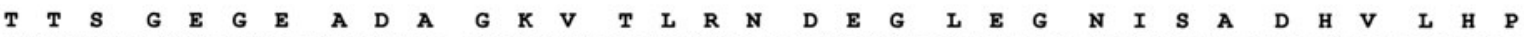
401 GACCACGTCT GGGGAAGGC AGGCAGATGC TGGGAAAGTA ACGCTGAGGA ACGATGAGGG CCTTGAGGGT AATATCTCAG CCGACCATGT TCTACATCCC

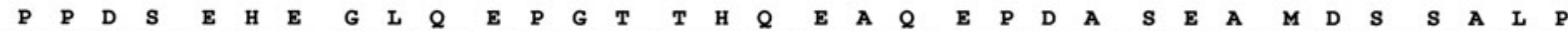
501 CCTCCTGACA GTGAACACGA GGGTTTGCAG GAACCGGGA CGACGCATCA GGAGGCGCAA GAACCAGACG CGAGTGAAGC AATGGACTCT TCCGCGCTAC

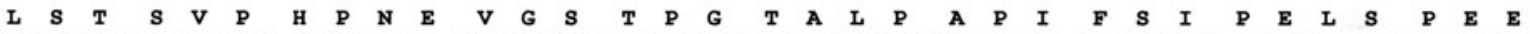
601 CACTTTCCAC GTCGgTACCA CATCCTAACG AAGTCGGTTC AACACCAGGA ACAGCGCTGC CTGCCCCGAT TTTTAGCATT CCAGAGCTCT CACCGGAGGA

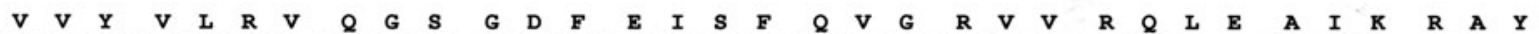
701 AgTTGTCTAC GTTTTACGG TTCAGGGTC AGGCGATTTC GAAATAGTT TCCAAGTAGg CCGGGTGGT AGGCAGTTGG AAGCCATCAA GAGAGCATAC

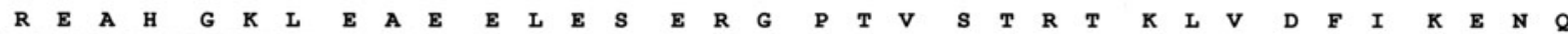
801 AGGGAGGCTC ACGGGAAGCT AGAAGCTGAG GAGCTGGAGT CGGAAAGGG ACCGACGGTT TCGACTCGGA CGAAACTAGT TGACTTTATC AAAGAAAAC

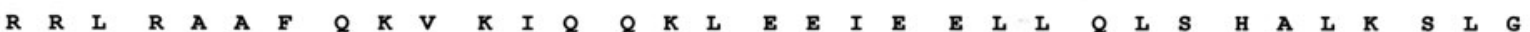
901 AGAGACGGCT GAGGGCGGG TTTCAGAAGg TTAAGATTCA GCAAAAGTTG GAGGAGATCG AgGAACTGTT GCAGCTGTCA CACGCACTAA AATCTCTAGG

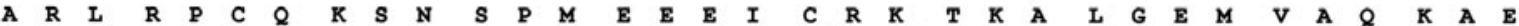
1001 TGCCCGCCTG AGACCCTGCC AAAAAAGTAA TTCCCCAATG GAGGAAGAGA TTTGTCGTAA GACGAAAGCT TTGGGCGAAA TGGTTGCCCA GAAAGCGGAG

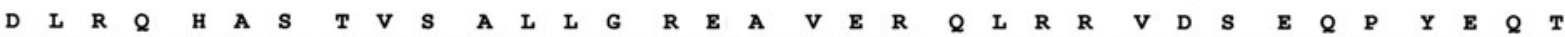
1101 GATCTTCGTC AGCATGCGTC AACTGTCTCG GCTCTGCTAG GTCGCGAAG TGTTGAGAGA CAGTTGCGGC GTGTCGACAG TGAACAACCC TATGAACAAA $\begin{array}{llllllllllllllllllllllllllllllllll}\text { D } & \text { A } & \text { G } & \text { V } & \text { A } & \text { A } & \text { R } & \text { A } & \text { E } & \text { E } & \text { F } & \text { R } & \text { K } & \text { A } & \text { L } & \text { E } & \text { K } & \text { A } & \text { A } & \text { S } & \text { G } & \text { A } & \text { R } & \text { Q } & \text { F } & \text { V } & \text { G } & \text { T } & \text { T } & \text { A } & \text { D } & \text { E } & \text { I }\end{array}$ 1201 CAGACGCCGG GGTTGCAGCC AGAGCAGAGG AATTTCGGAA GGCACTGGAG AAAGCAGCTT CCGGTGCGAG ACAATTCGTG GGGACCACAG CGGACGAAAT

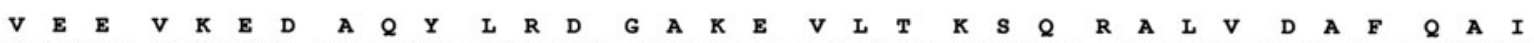

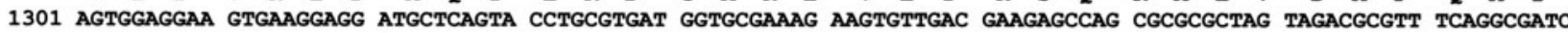

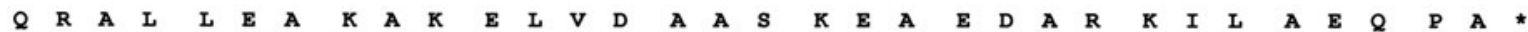
1401 CAAAGGGTC TACTGGAGG GAAGGCAAAG GAGCTCGTAG ATGCCGCATC AAAGGAAGCT GAAGACGCTC GTAAGATCTT AGCGGAACAG CCAGCGTGAt

1501 tcgccgagga cgaagttggt aatgcacggt gaatgagggt tggtcatcce aatcccage ttgatagcgt cacgtgggtt tttcgccggg gaaacgatca 1601 ttagggaggt gatgtatcge agtaaacatg ggcatatcag caccagtttt tttacatgtg agggatggga tccagtgtag gtgtaaggga cagctgtctt 1701 tcaaatttgg gettoggttg cogctccogt tctttcagca tatgtacagg tatgtacagt gaataagtgc gtgggccaat gtgctctcat caatcatgta 1801 cagaacatat gttttggtca tatctatgca gegcetgcat gagcceatgc cgctcgtgtt ttacgaagcc agatgcggtg ccgccetgtc ccagctacac

1901 atgctgtgca cggggaacaa cggccatgtt ggaaagtca ctgttttata aatgattgac aactaatgaa aaagcactca agcgggaaat gtttcatgcg 2001 gtccaaagag caggggggaa agtcactgtt ttataaatga ttgtgacaac tatctaatga aaagcactc aagcgggaaa tgtttcatgc ggtccaaaga $-x \longrightarrow$

2101 gtagggggcg ggcgtggtac tgatgattac cgcgtaacaa tgaccacgce ggcgcagatg togcagtgct gtagcgtttg atgttctttt gtatggcgga 2201 agggtgacaa ggcaaacggc gagagtcgac ttacagactc accaccgggc aaccatcggt tccoaggto ataagctgga ctattgtc(a).

Fig. 1. The cDNA encoding NcMAG1. The largest cDNA clone (GenBank Accession no. EF580924, bottom) is represented together with the deduced MAG1 precursor protein (GenBank Accession no. ABQ52425, top). The predicted signal peptide cleavage site is indicated by a filled arrowhead. The 5'- and 3'-UTRs are in lowercase with the two nucleotides differing from the ApiDots DT.92484705 transcript underlined. Nucleotide residues at which polyadenylation was observed in other cloned NcMAG1 cDNAs are shaded in grey. Sequences differing at most by 1 nucleotide from the consensus polyadenylation signal (AATAAA) are boxed. Tandem repeat units (NT 1931-2016 and 2017-2107) present in the 3 '-UTR are shown as horizontal arrows above the nucleotide sequence. Mismatches and gaps created to align the two repeat units are displayed as ' $x$ '.

\section{Expression and immunolocalization of NcMAG1} in N. caninum tachyzoites and bradyzoites

A recombinant protein (recNcMAG1), comprising aa 31-394, was expressed as a (His) ${ }_{6}$-tagged fusion protein in $E$. coli and used to immunize rabbits. All intermediate and final bleeds had a high titre against the purified recombinant protein as determined by Western blot and ELISA (data not shown). Sera from the third bleed were affinity-purified against recNcMAG1 and used for all further experiments.

In Western blots of protein extracts from purified extracellular N. caninum, anti-NcMAG1 antibodies detected a $\sim 67 \mathrm{kDa}$ band. The band was more prominent in lysates from SNP-treated cultures (containing predominantly bradyzoites) than in tachyzoite lysates (Fig. 3, lanes 1 and 2). Similarly, the protein was much more abundant in lysates of SNP-treated Neospora-infected Vero cells compared to untreated, infected cells (Fig. 3, lanes 3 and 4). The antibodies did not show any reactivity with uninfected Vero cell lysates (Fig. 3, lanes 5 and 6).

Affinity-purified antibodies were then used to localize NcMAG1 by IF and TEM. IF detection of MAG1 in extracellular parasites showed that the protein was distributed in a punctuated pattern 


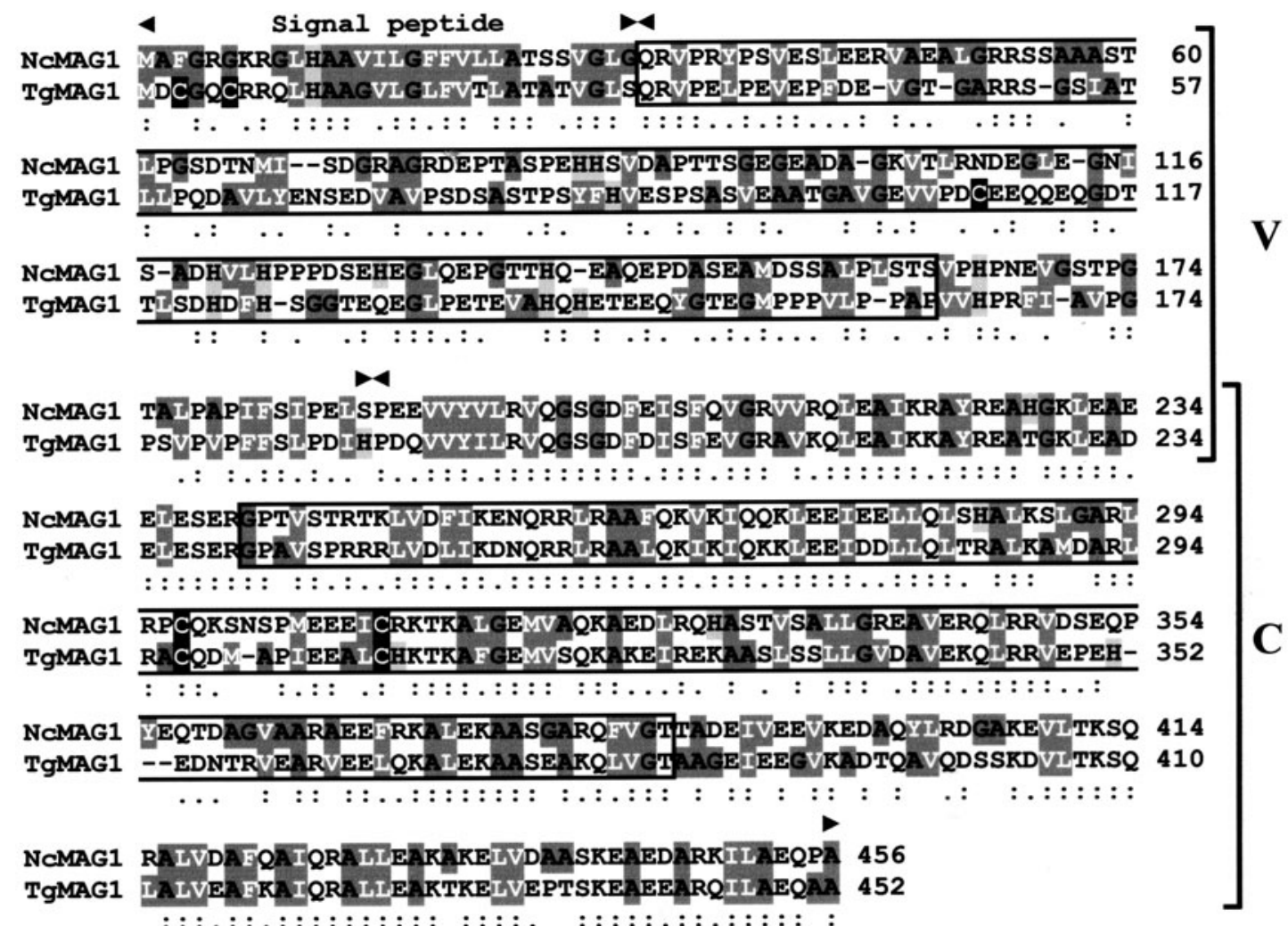

Fig. 2. Protein sequence alignment of deduced MAG1 precursors. Neospora caninum (Nc; GenBank Accession no. ABQ52425, this work) and Toxoplasma gondii (Tg; GenBank Accession no. AAC46484) MAG1 predicted protein sequences (single letter code) were aligned with MUSCLE and shaded according to the MM5 reduced, 5-letter amino acid alphabet. Residue grouping is as follows: [C]; [FILMVWY]; [AG]; [H]; [DEKNPQRST]. Identical residues are indicated by colons, similar residues are marked by dots. The putative signal peptide was identified with SignalP 3.0. Boundaries between the predicted signal peptide, the conserved (C) C-terminal region (66\% identity, aa 189-456) and the less conserved (V) N-terminal region of NcMAG1 (32\% identity, aa 31-188) are indicated by filled arrowheads. Antibodies were raised against a large portion of a recombinant NcMAG1 (aa 31-394, not shown). Amino acid stretches within the $\mathrm{V}$ and $\mathrm{C}$ regions, which were used for affinity-purification of antibodies specific to these regions are boxed.

within the cytoplasm. These punctuations were more apparent in bradyzoites (Fig. 4A). Staining of intracellular tachyzoites detected the protein mostly within the lumen of the parasitophorous vacuole (PV); the PV periphery was also faintly labelled. In contrast, after triggering tachyzoite-to-bradyzoite conversion with SNP, a more pronounced staining of the cyst wall and the cyst matrix was observed (Fig. 4B and C). The efficiency of the in vitro stage conversion using SNP treatment was confirmed using the bradyzoite-specific marker BAG1 on Neospora-infected cells (Fig. 4B) and on purified parasites (Fig. 4D). In a double-labelling experiment with anti-recNcMAG1 and $\mathrm{mAbCC} 2$, a monoclonal antibody directed against a cyst-specific antigen, both antigens appeared to largely co-localize (Fig. 4C)

By immunogold-TEM, performed on keratinocytes infected with $N$. caninum tachyzoites, minor labelling was observed in the intra-parasitic space, the lumen of the $\mathrm{PV}$, and within the dense granule organelles of the tachyzoites (Fig. 5A). Staining of cell cultures undergoing SNP-treatment and hence tachyzoite-to-bradyzoite stage conversion (Fig. 5B-D) exhibited a much more pronounced immunogold staining. Gold particles were abundant within the cyst matrix and, in many cysts, also on the cyst wall. In addition, dense granule (DG) organelles were intensely labelled (Fig. 5B-D), indicating an increased expression of NcMAG1 during stage conversion, or an accumulation of the protein due to reduced degradation.

Antibodies against the NcMAG1 conserved region, but not the variable region, cross-react with TgMAG1

Since NcMAG1 and TgMAG1 are orthologous proteins, we investigated the potential antibodycross-reactivity of these antigens. Immunoblot and immunofluorescence using affinity-purified antibodies against the recombinant NcMAG1 resulted in a weak, but distinct, cross-reactivity with T. gondii, no matter whether cultures had been treated with $100 \mu \mathrm{M}$ SNP or not (data not shown). We thus determined, which region (conserved or variable) could 


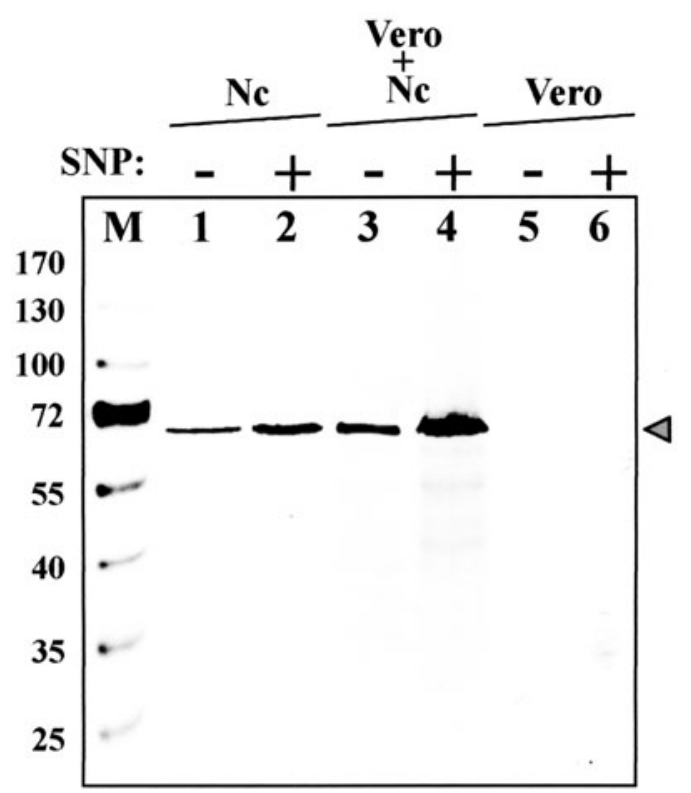

Fig. 3. Western blot analysis of NcMAG1 expression in Neospora caninum. Affinity-purified antibodies raised against a recombinant NcMAG1 were used to detect the protein in lysates obtained from free parasites $(\mathrm{Nc})$, Neospora-infected Vero cells (Vero $+\mathrm{Nc}$ ), and uninfected Vero cells (Vero). Cultures were either left non-treated (-) or treated for 9 days with SNP $(+)$. Lanes 1 and 2: lysates from $2 \times 10^{5}$ free $N$. caninum; lanes 3 and $4: N$. caninum-infected Vero cells lysates containing $5 \times 10^{4}$ parasites. Total protein concentrations in control lanes 5 and 6 were adjusted to fit those in lanes 3 and 4, respectively. M: pre-stained protein marker; apparent MWs in $\mathrm{kDa}$ are indicated. The open arrowhead indicates the position of the $67 \mathrm{kDa}$ NcMAG1 band.

be responsible for this cross-reactivity. Western blots were performed, using extracts of non-treated or SNP-treated Neospora- and Toxoplasma-infected cells. In order to enhance the detection of any weak cross-reactivity, the samples loaded from Toxoplasma-infected cells contained 5 times more parasites than those loaded from Neospora-infected cells (non-treated cells: $10^{5}$ Neospora and $5 \times 10^{5}$ Toxoplasma; SNP-treated cells: $10^{4}$ Neospora and $5 \times 10^{4}$ Toxoplasma). Even though the Toxoplasma samples were more concentrated in terms of parasite numbers, the $65 \mathrm{kDa}$ TgMAG1 was only faintly detected by the antibodies affinity-purified on the conserved region of NcMAG1 in both non-treated and SNP-treated cultures (Fig. 6A, upper panel, lanes 3 and 7). In contrast, no cross-reactivity in extracts containing Toxoplasma was observed when antibodies affinity-purified on the variable region were used (Fig. 6A, lower panel, lanes 3 and 7). Note that the $67 \mathrm{kDa}$ NcMAG1 was recognized by both affinity-purified antibodies in Neospora-infected cells (Fig. 6A, lanes 1 and 5). These results were largely confirmed by IF performed on infected cells after treatment with SNP (Fig. 6B) or without treatment (not shown). Antibodies directed against the variable region of NcMAG1 failed to detect $T$. gondii in spite of an exposure time 20 times longer than what was used for the detection of Neospora.

\section{DISCUSSION}

The apicomplexan EST database (Li et al. 2003, 2004) allowed retrieval of the NcMAG1 sequence and amplification of the corresponding cDNA by RACE. The 3 '-ends of the NcMAG1 transcripts were highly heterogeneous in size, strongly suggesting that polyadenylation occurs at multiple sites. Interestingly, a number of $N c M A G 1$ mRNA properties were reminiscent of $T$. gondii dihydrofolate reductase (DHFR) mRNA. Common features include the heterogeneity of the 3 '-end lengths, the absence of a consensus AATAAA polyadenylation signal downstream of the coding sequence, and the presence of a direct repeat in the 3'-UTR (Matrajt et al. 2004). Half of the NcMAG1 transcripts sequenced were polyadenylated within 10-30 NT downstream of sequences differing at most by 1 NT from the consensus AATAAA hexamer. This suggests that apicomplexan parasites, similarly to mammals, may use, in addition to the consensus AATAAA, some of its single N'T sequence variants. In the other half of the transcripts that we analysed, there was no evident sequence reminiscent of a consensus hexamer within 10-30 NT upstream of the polyadenylation site, suggesting that, similar to that observed in yeast, a variety of other positioning elements might also be used (Guo and Sherman, 1995). In the DHFR transcript, the direct repeat in the 3 '-UTR was found to exert a slight stimulatory effect on chloramphenicol acetyltransferase (CAT) expression in a CAT reporter assay (Matrajt et al. 2004). In this context, it would be of interest to assess whether the 84/90 NT direct repeat present in NcMAG1 3'-UTR would produce a similar effect.

The deduced amino acid sequences of $T$. gondii and $N$. caninum MAG1 share $54 \%$ identity and each protein contains a single 30 aa hydrophobic domain, which is located at the $\mathrm{N}$-terminus and represents a predicted signal peptide. Since TgMAG1 and NcMAG1 do not exhibit any significant similarity with other proteins, it remains rather difficult to postulate a biological function for these proteins at present. Given their relative abundance in the tissue cysts of $T$.gondii and $N$. caninum, they could possibly exert a scaffolding role. In addition, the rather conserved C-terminal region of MAG1 in the two closely related parasites suggests that this part of the protein could be involved in common functional activities.

To date, information concerning the composition of $N$. caninum tissue cysts is limited, since they have not been really amenable to experimental procedures. A protocol based on the SNP treatment described by Vonlaufen et al. (2004) was used to produce $N$. caninum tissue cysts in vitro. In this way, 


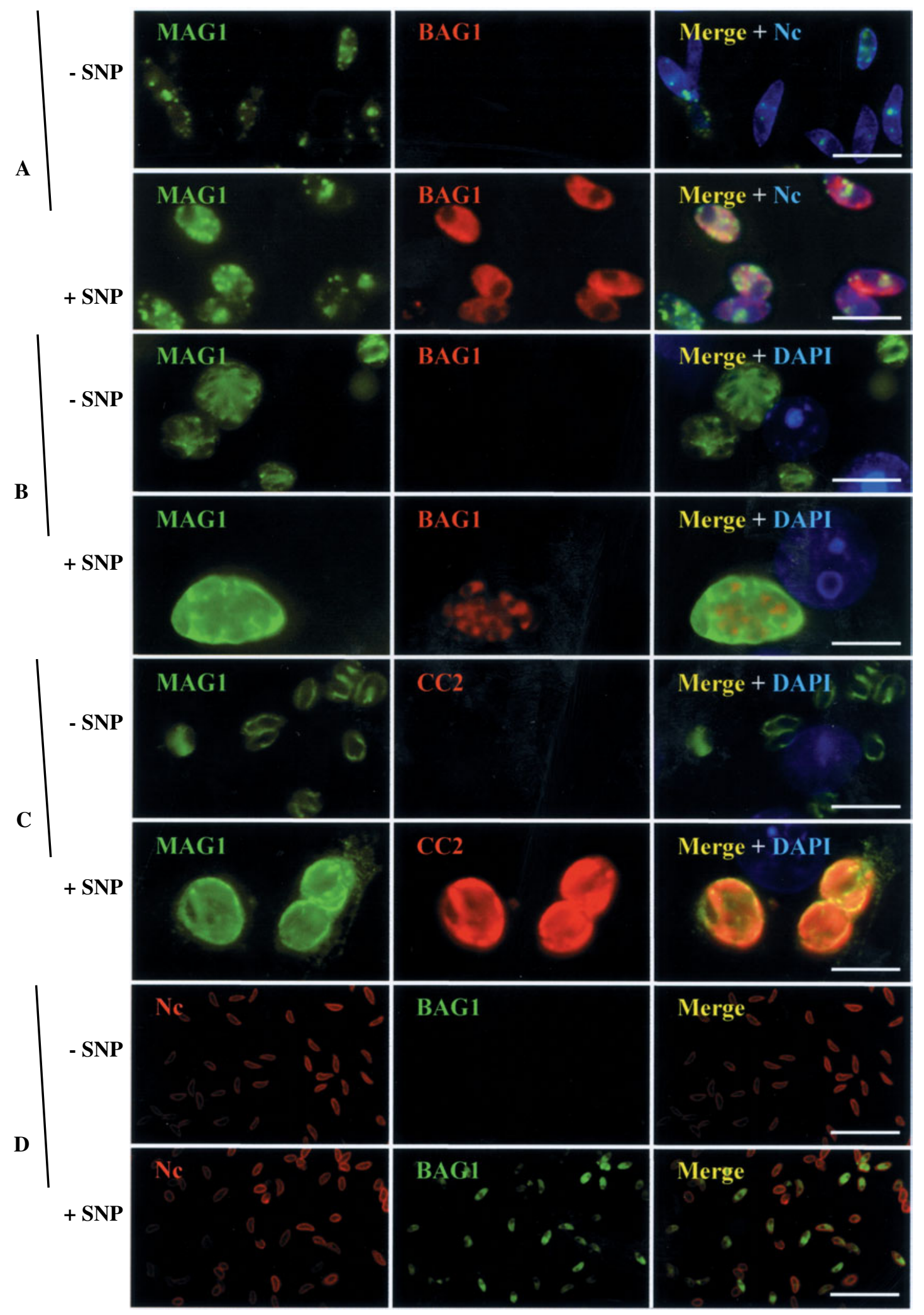

Fig. 4. Immunofluorescence analysis of NcMAG1 expression. Neospora caninum were cultured in non-treated (-SNP) or in SNP-treated Vero cells $(+\mathrm{SNP})$, and analysed by indirect IF, either within infected host cells $(\mathrm{B}-\mathrm{C})$ or after purification from host cells (A and D). The primary antibodies were: anti-NcMAG1 affinity-purified polyclonal antibodies (MAG1), a polyclonal antibody directed against the bradyzoite-specific marker BAG1 (BAG1), the monoclonal antibody $\mathrm{CC} 2$ directed against a cyst-specific antigen (CC2), and an antiserum directed against N. caninum crude extract $(\mathrm{Nc})$. The following secondary Alexa Fluor (AF)-labelled antibodies were used: AF-350 (blue), AF-488 (green) and AF-568 (red). An overlay image with DAPI staining of nuclei (B-C, blue) or with AF-350 staining of whole parasites (A, blue) is presented on the right panel. Scale bars $=5,10$ and $20 \mu \mathrm{m}$ in panels (A), (B-C), and (D), respectively. 

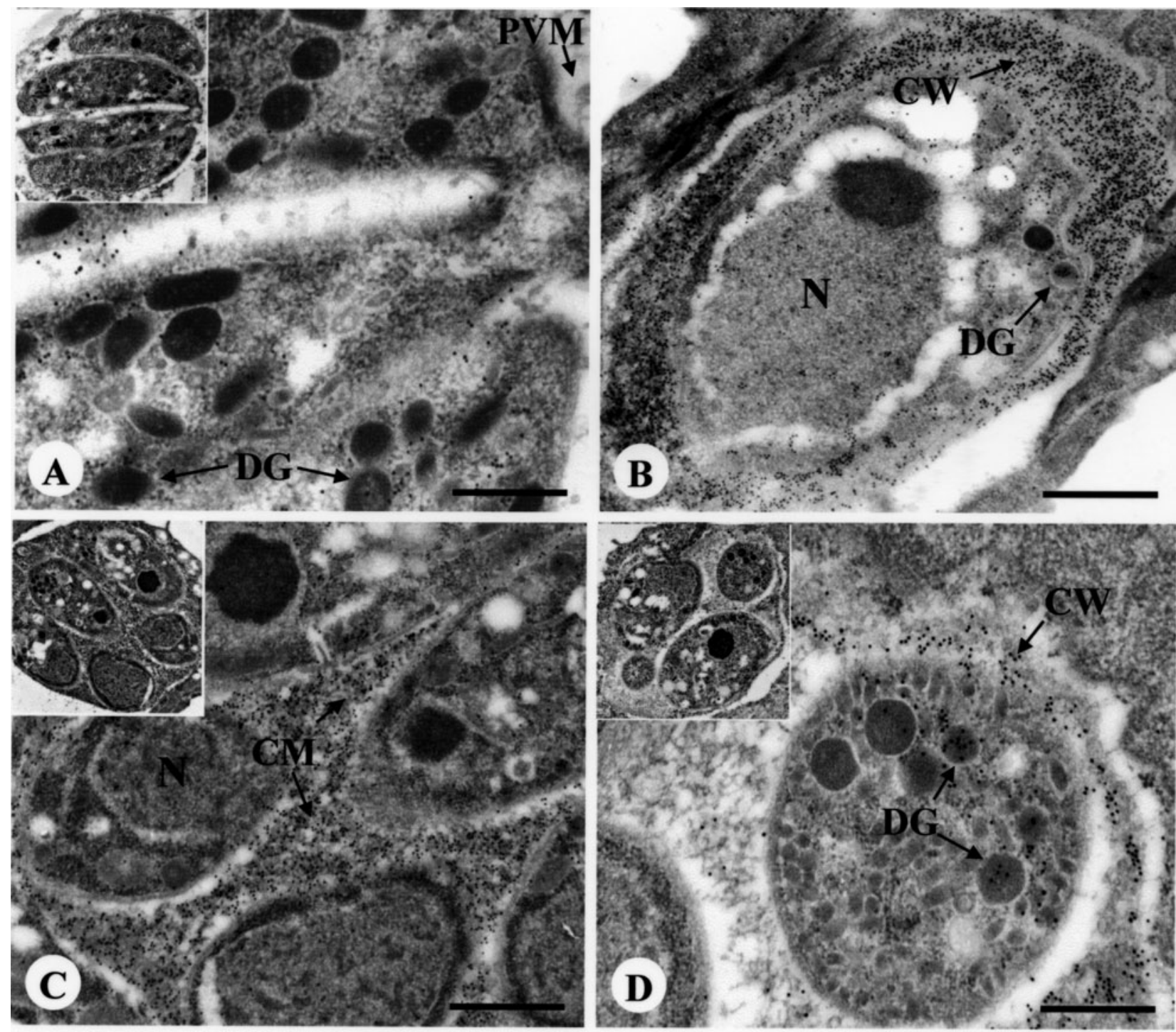

Fig. 5. Immunolocalization of NcMAG1 by immunogold EM. TEM on Neospora caninum-infected mouse epidermal keratinocytes using affinity-purified anti-NcMAG1 primary antibodies. (A) Parasitophorous vacuole containing tachyzoites. Note the relatively marginal staining of the tachyzoite dense granules (DG) and the vacuolar space between the parasites. PVM, Parasitophorous vacuole membrane. (B-D) Cyst-like vacuoles obtained after SNP-treatment. Cysts containing either a single parasite $(\mathrm{B})$ or several parasites $(\mathrm{C}$ and $\mathrm{D})$. Note the massive immunogold labelling within the cyst matrix $(\mathrm{CM})$, the dense granules $(\mathrm{DG})$ and the cyst wall $(\mathrm{CW}) . \mathrm{N}$ depicts the nucleus, which remains virtually unlabelled. Scale bars $=0 \cdot 25 \mu \mathrm{m}$ in $(A)$ and $(D)$ and $0 \cdot 4 \mu \mathrm{m}$ in $(B)$ and $(C)$. Inserts in (A), (C) and (D) represent the corresponding low-magnification views.

we could achieve up to $70 \%$ tachyzoite-to-bradyzoite conversion, as demonstrated by staining with antibodies directed against the bradyzoite-specific BAG1 marker (McAllister et al. 1996). The high percentage of stage conversion we achieved corroborates the validity of the comparison of NcMAG1 expression levels between tachyzoites and bradyzoites.

Immunoblotting of lysates from purified parasites of either tachyzoite or bradyzoite-converted cultures showed a similar $67 \mathrm{kDa}$ band reacting with antiNcMAG1 antibodies. This sharply contrasted with the predicted MW of the mature NcMAG1 $(50.5 \mathrm{kDa})$. A difference between the predicted and the apparent MW of the protein was also observed in TgMAG1 (Parmley et al. 1994). This difference could, at least partially, be explained by posttranslational modifications such as extensive glycosylations and/or phosphorylations. However, since the recombinant NcMAG1 expressed in E. coli also displayed an aberrant apparent MW in SDS-PAGE ( $65 \mathrm{kDa}$ instead of the predicted $41 \mathrm{kDa})$, it is very likely that the main clue to the electrophoretic mobility shift lies within the protein sequence itself. The $67 \mathrm{kDa}$ NcMAG1 product was more prominent in purified bradyzoites than in tachyzoites, indicating an increase in expression and/or a decrease of the protein turnover (degradation) resulting in a net 
(A)

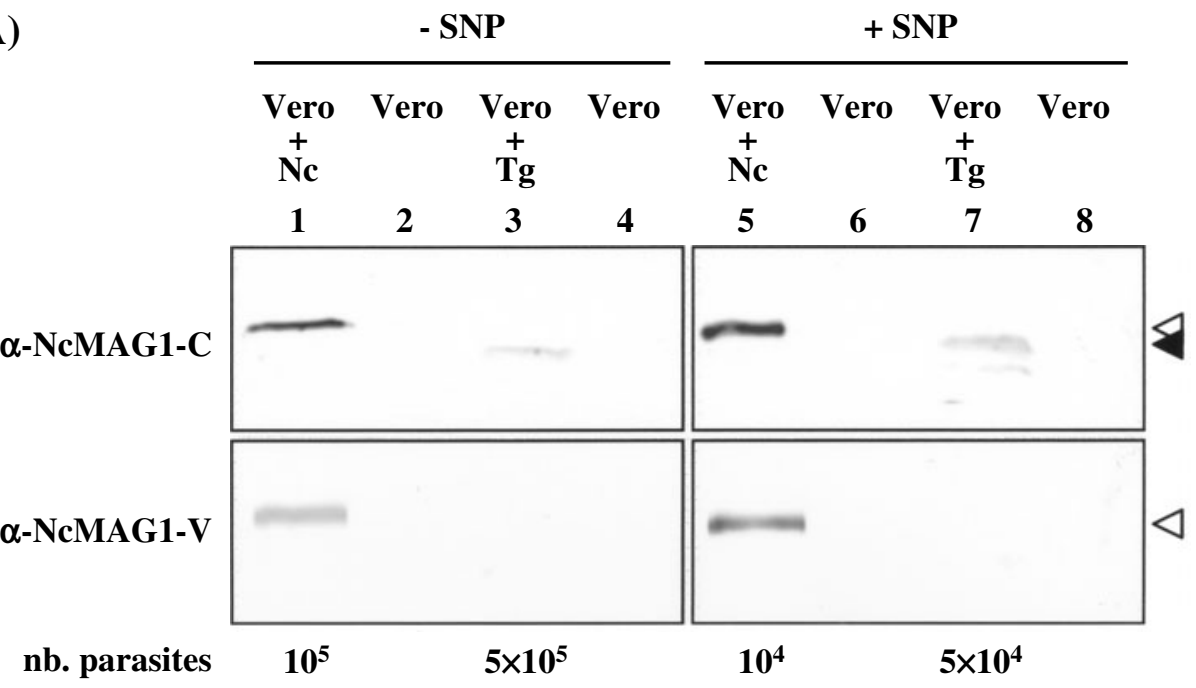

(B)

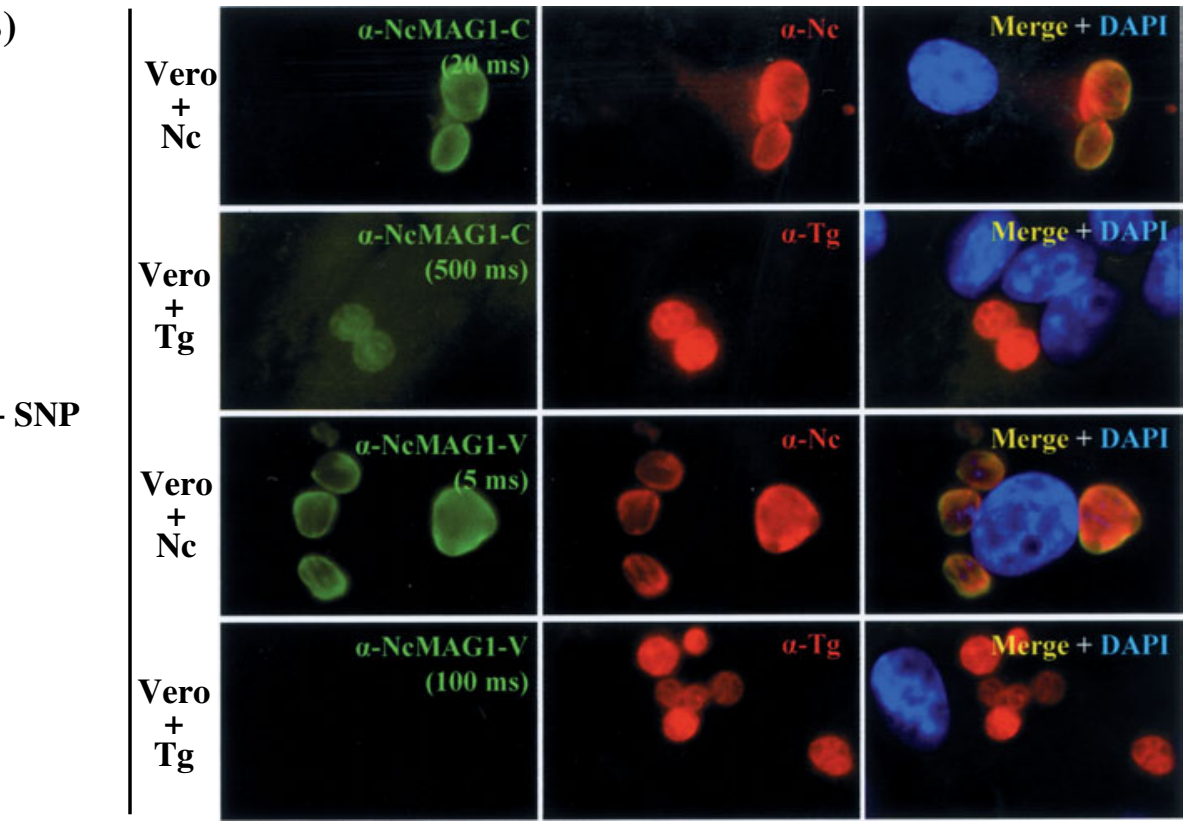

Fig. 6. Cross-reactivity of antibodies directed to the conserved or the variable region of NcMAG1. Polyclonal antiNcMAG1 antibodies were affinity-purified on recombinant proteins corresponding to either the conserved (C) or the variable $(\mathrm{V})$ region of NcMAG1. The cross-reactivity of the resulting antibodies $(\alpha-\mathrm{NcMAG} 1-\mathrm{C}$ and $\alpha-\mathrm{NcMAG} 1-\mathrm{V})$ was assessed on Neospora caninum- (Vero $+\mathrm{Nc}$ ) and Toxoplasma gondii-infected (Vero + Tg) Vero cells. (A) Western blot analysis. Infected cell cultures were either left non-treated (-SNP) or treated with SNP to trigger tachyzoite to bradyzoite conversion $(+\mathrm{SNP})$. The number of parasites present in infected cell lysates is indicated. Total protein concentrations in uninfected control extracts (Vero; even lanes), were adjusted to match those in the corresponding infected cell extracts (odd lanes). The open and filled arrowheads indicate the positions of the $67 \mathrm{kDa}$ NcMAG1 and the $65 \mathrm{kDa}$ TgMAG1 bands, respectively. (B) Immunofluorescence analysis. N. caninum or T. gondii were cultured in SNP-treated Vero cells and analysed by indirect IF using $\alpha$-NcMAG1-C or $\alpha$-NcMAG1-V (green) and an antiserum directed against either $N$. caninum $(\alpha-\mathrm{Nc})$ or T. gondii $(\alpha-\mathrm{Tg})$ crude extracts (red). Overlay images with DAPI staining of nuclei (blue) are presented on the right. Green channel photographs were not enhanced post-acquisition; the respective exposure times are indicated.

accumulation of NcMAG1 in the developing cyst matrix and wall.

The higher steady-state level of NcMAG1 in bradyzoites was also confirmed by IF analysis. Similarly to TgMAG1 (Ferguson and Parmley, 2002), NcMAG1 was highly abundant within tissue cysts.
The increase of NcMAG1 staining during stage conversion was paralleled by that of BAG1 within the parasite cytoplasm. The staining obtained with $\mathrm{mAb}$ $\mathrm{CC} 2$ and anti-NcMAG1 antibody also simultaneously increased during stage conversion, and the two antigens appeared to largely co-localize. The 
antigen detected by mAb CC2 in cysts has not yet been identified, but it is nevertheless unlikely that the co-localization we observed was due to the binding of mAb CC2 to MAG1. Indeed, mAb CC2 recognizes a $115 \mathrm{kDa}$ glycosylated cyst antigen (Gross et al. 1995), a MW, which does not fit with the apparent MW of neither NcMAG1 $(\sim 67 \mathrm{kDa})$ nor TgMAG1 $(65 \mathrm{kDa})$ in bradyzoites. Therefore, NcMAG1 represents a reliable marker for the detection of tachyzoite-to-bradyzoite stage conversion.

Immunogold TEM confirmed the IF results and revealed the presence of NcMAG1 within the cyst wall and the cyst matrix, which was much more pronounced compared to the labelling of the PV of tachyzoite-infected cells. Importantly, the ultrastructural study revealed that NcMAG1 was also localized within DG. Taken together, our results suggest that NcMAG1 is targeted to the DG and subsequently released into the parasitophorous vacuole in a process that is upregulated during tachyzoite-bradyzoite stage conversion and cyst formation.

The fact that MAG1 is targeted to the cyst wall and the cyst matrix following secretion from the DG organelles was not surprising since the incorporation of DG proteins into the cyst wall during cyst biogenesis has already been reported for other proteins such as NcGRA1, NcGRA2 and NcGRA7, as well as for the antigen recognized by mAb CC2, (Fuchs et al. 1998; Vonlaufen et al. 2002, 2004). With the exception of a few DG proteins, for which the function is known (such as NTPases, cyclophilins and serine protease inhibitors) the majority of these GRA proteins, including $T$. gondii GRA1-10 and $N$. caninum GRA1, 2, 3, 6, and 7, do not exhibit sequence similarities with other known proteins (Adjogble et al. 2004; Ahn et al. 2005; Mercier et al. 2005). Moreover, their function remains largely unknown, except for TgGRA7, which participates in sequestering host cell lysosomes into the vacuolar space by acting like a garrote. However, this process does apparently not occur in $N$. caninum (Coppens et al. 2006).

GRA proteins share a few common features, including a signal peptide that appears to be sufficient to target the proteins to DG organelles and, being ubiquitous (Mercier et al. 2005) was predicted in the NcMAG1 primary sequence. An additional characteristic of GRA proteins that was also observed in MAG1 is the intriguing difference between the MW predicted from the protein primary sequence and the higher MW observed on SDS-PAGE gels (Mercier et al. 2005). A trans-membrane domain present in most (TgGRA3-10), but not all GRA proteins (Ahn et al. 2005; Mercier et al. 2005) was, however, not found in NcMAG1.

Interestingly, even though MAG1 is more abundant in bradyzoites and accumulates into cysts that define the chronic stage of infection, it was described as an antigen detected promptly after infection with T. gondii. Di Cristina et al. (2004) showed that a fragment of MAG1 (aa 28-126, therefore within the region we refer to as 'variable') is highly immunogenic and triggers a $\mathrm{B}$-cell response in $73 \%$ of healthy individuals. The immune response against MAG1 is rapid, appearing as early as 1 month after infection (Di Cristina et al. 2004). Recombinant TgMAG1 was also tested, with encouraging results, in order to improve current serodiagnostic methods of acute toxoplasmosis during pregnancy (Pfrepper et al. 2005; Holec et al. 2007).

Two studies have so far reported that an efficient, although partial, protection against challenge with $T$. gondii cysts could be obtained, as evidenced by a marked reduction in the number of cerebral cysts following immunization with TgMAG1 alone (Parmley et al. 2002) or combined with a bradyzoitespecific antigen (Nielsen et al. 2006). In the first study, Parmley et al. demonstrated that vaccination with the 79-aa C-terminal part of TgMAG1 significantly increased the survival rate of animals and reduced the number of cerebral cysts by as much as about 3-fold. In the second study, Nielsen et al. observed an effective protection after DNA vaccination with a mixture of 2 plasmid vectors encoding TgMAG1 and the bradyzoite-specific TgBAG1. A preferential induction of antibodies of the $\operatorname{IgG} 2 \mathrm{a}$ subclass directed against the immunizing antigens was also observed (Nielsen et al. 2006). Altogether, these results indicate that MAG1 could be a useful antigen for diagnosis, as well as a promising candidate for vaccination trials in $T$. gondii.

Recently, the use of NcMAG1 as a vaccine was assessed in an acute disease mouse model for neosporosis (Debache et al. 2009). In this experiment, mice were vaccinated either intraperitoneally or intranasally and, following challenge infection with $N$. caninum tachyzoites, a partial $(50 \%)$ protection was observed for the intraperitoneally vaccinated animals, while only $10 \%$ of animals survived the challenge following intranasal vaccination. However, application of NcMAG1 as a vaccine will make more sense in the context of re-activation of neosporosis in chronically infected animals harbouring tissue cysts, or the challenge should ideally be performed by oral administration of tissue cysts. This procedure appeared to be difficult to carry out since, at present, only a limited number of studies have demonstrated the possibility to produce $N$. caninum cysts in immunosuppressed mice (McGuire et al. 1997; Rettigner et al. 2004). Thus, a more suitable experimental model than the mouse, such animals possessing the ability to develop cerebral tissue cysts, should preferentially be used.

Even though the MAG1 primary sequences in $T$. gondii and N. caninum share a high degree (66\%) of identity at their C-termini, only limited, but still clear, antibody cross-reactivity was observed in 
Toxoplasma when anti-NcMAG1 antibodies affinitypurified on the relatively conserved C-terminal region were tested. No cross-reactivity was found when antibodies affinity-purified on the variable region were assessed. Both affinity-purified antibodies reacted with $N$. caninum tachyzoites and bradyzoites. This indicates that only the variable but not the conserved region of the protein could be an ideal tool for distinguishing between Toxoplasma and Neospora species, and corresponding investigations are currently being carried out to investigate the serodiagnostic potential of the NcMAG1 variable region.

\section{ACKNOWLEDGEMENTS}

D. Williams and A. J. Trees (University of Liverpool) are gratefully acknowledged for providing the Nc-Liverpool isolate. We are indebted to $\mathrm{W}$. Bohne and $\mathrm{U}$. Gross (University of Götttingen) for providing $\mathrm{mAbCC} 2$, and to M. McAllister (University of Illinois) for the gift of antiBAG1 antiserum.

\section{F I NANCIAL SUPPORT}

This study was supported by the Vetsuisse Faculty (University of Bern), and the Swiss National Science Foundation (grants No. 3100A0-112532/1 and 31003A127374/1).

\section{REFERENCES}

Abramoff, M. D., Magelhaes, P. J. and Ram, S. J. (2004). Image processing with Image J. Biophotonics International 11, 36-42.

Adjogble, K. D., Mercier, C., Dubremetz, J. F., Hucke, C., Mackenzie, C. R., Cesbron-Delauw, M. F. and Daubener, W. (2004). GRA9, a new Toxoplasma gondii dense granule protein associated with the intravacuolar network of tubular membranes. International Fournal for Parasitology 34, 1255-1264.

Aguado-Martinez, A., Alvarez-Garcia, G., Fernandez-Garcia, A., Risco-Castillo, V., Marugan-Hernandez, V. and Ortega-Mora, L. M. (2009). Failure of a vaccine using immunogenic recombinant proteins $\mathrm{rNcSAG} 4$ and $\mathrm{rNcGRA} 7$ against neosporosis in mice. Vaccine 27, 7331-7338. doi: 10.1016/S0264-410X(09)01384-X.

Ahn, H. J., Kim, S. and Nam, H. W. (2005). Host cell binding of GRA10, a novel, constitutively secreted dense granular protein from Toxoplasma gondii. Biochemical and Biophysical Research Communications 331, 614-620.

Altschul, S. F., Gish, W., Miller, W., Myers, E. W. and Lipman, D. J. (1990). Basic local alignment search tool. Fournal of Molecular Biology 215, 403-410.

Ausubel, F. M., Brent, R., Kingston, R. E., Moore, D. D., Seidman, J. G., Smith, J. A. and Struh1, K. (1997). Current Protocols in Molecular Biology. John Wiley \& Sons, Somerset, UK.

Barber, J. S., Holmdahl, O. J., Owen, M. R., Guy, F., Uggla, A. and Trees, A. J. (1995). Characterization of the first European isolate of Neospora caninum (Dubey, Carpenter, Speer, Topper and Uggla). Parasitology 111, 563-568.
Bendtsen, J. D., Nielsen, H., von Heijne, G. and Brunak, S. (2004). Improved prediction of signal peptides: SignalP 3.0. Fournal of Molecular Biology 340, 783-795.

Beyer, T. V., Svezhova, N. V., Radchenko, A. I. and Sidorenko, N. V. (2002). Parasitophorous vacuole: morphofunctional diversity in different coccidian genera (a short insight into the problem). Cell Biology International 26, 861-871.

Bohne, W., Heesemann, J. and Gross, U. (1994). Reduced replication of Toxoplasma gondii is necessary for induction of bradyzoite-specific antigens: a possible role for nitric oxide in triggering stage conversion. Infection and Immunity 62, 1761-1767.

Bonfield, J. K., Smith, K. and Staden, R. (1995). A new DNA sequence assembly program. Nucleic Acids Research 23, 4992-4999.

Chou, Q., Russell, M., Birch, D. E., Raymond, J. and Bloch, W. (1992). Prevention of pre-PCR mis-priming and primer dimerization improves low-copy-number amplifications. Nucleic Acids Research 20, 1717-1723.

Contini, C., Cultrera, R., Seraceni, S., Segala, D., Romani, R., Fainardi, E., Cinque, P., Lazzarin, A. and Delia, S. (2002). The role of stage-specific oligonucleotide primers in providing effective laboratory support for the molecular diagnosis of reactivated Toxoplasma gondii encephalitis in patients with AIDS. Fournal of Medical Microbiology 51, 879-890.

Coppens, I., Dunn, J. D., Romano, J. D., Pypaert, M., Zhang, H., Boothroyd, J. C. and Joiner, K. A. (2006). Toxoplasma gondii sequesters lysosomes from mammalian hosts in the vacuolar space. Cell 125, 261-274.

Debache, K., Guionaud, C., Alaeddine, F. and Hemphill, A. (2009). Intraperitoneal and intra-nasal vaccination of mice with three distinct recombinant Neospora caninum antigens results in differential effects with regard to protection against experimental challenge with Neospora caninum tachyzoites. Parasitology 137, 229-240. doi : 10.1017/S0031182009991259.

Di Cristina, M., Del Porto, P., Buffolano, W., Beghetto, E., Spadoni, A., Guglietta, S., Piccolella, E., Felici, F. and Gargano, N. (2004). The Toxoplasma gondii bradyzoite antigens BAG1 and MAG1 induce early humoral and cell-mediated immune responses upon human infection. Microbes and Infection 6, 164-171.

Dubey, J. P., Buxton, D. and Wouda, W. (2006). Pathogenesis of bovine neosporosis. Fournal of Comparative Pathology 134, 267-289.

Dubey, J. P., Carpenter, J. L., Speer, C. A., Topper, M. J. and Uggla, A. (1988). Newly recognized fatal protozoan disease of dogs. Fournal of the American Veterinary Medical Association 192, 1269-1285.

Edgar, R. C. (2004). MUSCLE: multiple sequence alignment with high accuracy and high throughput. Nucleic Acids Research 32, 1792-1797.

Ferguson, D. J. (2004). Use of molecular and ultrastructural markers to evaluate stage conversion of Toxoplasma gondii in both the intermediate and definitive host. International Fournal for Parasitology 34, 347-360.

Ferguson, D. J., and Parmley, S. F. (2002). Toxoplasma gondii MAG1 protein expression. Trends in Parasitology 18,482 . 
Fuchs, N., Sonda, S., Gottstein, B. and Hemphill, A. (1998). Differential expression of cell surface- and dense granule-associated Neospora caninum proteins in tachyzoites and bradyzoites. Fournal of Parasitology 84, 753-758.

Gondim, L. F., McAllister, M. M., Pitt, W. C. and Zemlicka, D. E. (2004). Coyotes (Canis latrans) are definitive hosts of Neospora caninum. International Fournal for Parasitology 34, 159-161.

Gross, U., Bormuth, H., Gaissmaier, C., Dittrich, C., Krenn, V., Bohne, W. and Ferguson, D. J. (1995).

Monoclonal rat antibodies directed against Toxoplasma gondii suitable for studying tachyzoite-bradyzoite interconversion in vivo. Clinical and Diagnostic Laboratory Immunology 2, 542-548.

Guo, Z. and Sherman, F. (1995). 3'-end-forming signals of yeast mRNA. Molecular and Cellular Biology 15, 5983-5990.

Hemphill, A. and Gottstein, B. (1996). Identification of a major surface protein on Neospora caninum tachyzoites. Parasitology Research 82, 497-504.

Hemphill, A. and Croft, S. L. (1997). Electron microscopy of parasites. In Analytical Parasitology (ed. Rogan, M. and Graig, P.), pp. 227-268. Springer Verlag, Heidelberg, Germany.

Hemphill, A., Gottstein, B. and Kaufmann, H. (1996). Adhesion and invasion of bovine endothelial cells by Neospora caninum. Parasitology 112, 183-197.

Hemphill, A., Vonlaufen, N. and Naguleswaran, A. (2006). Cellular and immunological basis of the hostparasite relationship during infection with Neospora caninum. Parasitology 133, 261-278. doi: 10.1017/ S0031182006000485.

Holec, L., Hiszczynska-Sawicka, E., Gasior, A., Brillowska-Dabrowska, A. and Kur, J. (2007). Use of MAG1 recombinant antigen for detection of Toxoplasma gondii infection in human. Clinical and Vaccine Immunology 14, 220-225.

Innes, E. A., Andrianarivo, A. G., Bjorkman, C., Williams, D. J. and Conrad, P. A. (2002). Immune responses to Neospora caninum and prospects for vaccination. Trends in Parasitology 18, 497-504.

Li, L., Crabtree, J., Fischer, S., Pinney, D., Stoeckert, C. J., Jr., Sibley, L. D. and Roos, D. S. (2004). ApiEST-DB: analyzing clustered EST data of the apicomplexan parasites. Nucleic Acids Research 32, D326-328.

Li, L., Brunk, B. P., Kissinger, J. C., Pape, D., Tang, K., Cole, R. H., Martin, J., Wylie, T., Dante, M., Fogarty, S. J., Howe, D. K., Liberator, P., Diaz, C., Anderson, J., White, M., Jerome, M. E., Johnson, E. A., Radke, J. A., Stoeckert, C. J., Jr., Waterston, R. H., Clifton, S. W., Roos, D. S. and Sibley, L. D. (2003). Gene discovery in the apicomplexa as revealed by EST sequencing and assembly of a comparative gene database. Genome Research 13, 443-454.

Matrajt, M., Platt, C. D., Sagar, A. D., Lindsay, A., Moulton, C. and Roos, D. S. (2004). Transcript initiation, polyadenylation, and functional promoter mapping for the dihydrofolate reductase-thymidylate synthase gene of Toxoplasma gondii. Molecular and Biochemical Parasitology 137, 229-238.

Matz, M., Shagin, D., Bogdanova, E., Britanova, O., Lukyanov, S., Diatchenko, L. and Chenchik, A.
(1999). Amplification of cDNA ends based on template-switching effect and step-out PCR. Nucleic Acids Research 27, 1558-1560.

McAllister, M. M., Parmley, S. F., Weiss, L. M., Welch, V. J. and McGuire, A. M. (1996). An immunohistochemical method for detecting bradyzoite antigen (BAG5) in Toxoplasma gondii-infected tissues cross-reacts with a Neospora caninum bradyzoite antigen. Fournal of Parasitology 82, 354-355.

McAllister, M. M., Dubey, J. P., Lindsay, D. S., Jolley, W. R., Wills, R. A. and McGuire, A. M. (1998). Dogs are definitive hosts of Neospora caninum. International Fournal for Parasitology 28, 1473-1478.

McGuire, A. M., McAllister, M. M., Jolley, W. R. and Anderson-Sprecher, R. C. (1997). A protocol for the production of Neospora caninum tissue cysts in mice. Fournal of Parasitology 83, 647-651.

Melo, F. and Marti-Renom, M. A. (2006). Accuracy of sequence alignment and fold assessment using reduced amino acid alphabets. Proteins 63, 986-995.

Mercier, C., Adjogble, K. D., Daubener, W. and Delauw, M. F. (2005). Dense granules: are they key organelles to help understand the parasitophorous vacuole of all apicomplexa parasites? International Fournal for Parasitology 35, 829-849.

Müller, N., Vonlaufen, N., Gianinazzi, C., Leib, S. L. and Hemphill, A. (2002). Application of real-time fluorescent PCR for quantitative assessment of Neospora caninum infections in organotypic slice cultures of rat central nervous system tissue. Fournal of Clinical Microbiology 40, 252-255.

Nicholas, K. B., Nicholas, H. B. J. and Deerfield, D. W. I. (1997). GeneDoc: analysis and visualization of genetic variation. EMBNEW News 4.

Nielsen, H. V., Di Cristina, M., Beghetto, E., Spadoni, A., Petersen, E. and Gargano, N. (2006). Toxoplasma gondii: DNA vaccination with bradyzoite antigens induces protective immunity in mice against oral infection with parasite cysts. Experimental Parasitology 112, 274-279.

Parmley, S., Slifer, T. and Araujo, F. (2002). Protective effects of immunization with a recombinant cyst antigen in mouse models of infection with Toxoplasma gondii tissue cysts. Fournal of Infectious Diseases 185 (Suppl 1), S90-S95

Parmley, S. F., Yang, S., Harth, G., Sibley, L. D., Sucharczuk, A. and Remington, J. S. (1994). Molecular characterization of a 65 -kilodalton Toxoplasma gondii antigen expressed abundantly in the matrix of tissue cysts. Molecular and Biochemical Parasitology 66, 283-296.

Pfrepper, K. I., Enders, G., Gohl, M., Krczal, D., Hlobil, H., Wassenberg, D. and Soutschek, E. (2005). Seroreactivity to and avidity for recombinant antigens in toxoplasmosis. Clinical and Diagnostic Laboratory Immunology 12, 977-982.

Reisch1, U., Bretagne, S., Kruger, D., Ernault, P. and Costa, J. M. (2003). Comparison of two DNA targets for the diagnosis of Toxoplasmosis by real-time PCR using fluorescence resonance energy transfer hybridization probes. BMC Infectious Diseases 3, 7 .

Rettigner, C., Leclipteux, T., De Meerschman, F., Focant, C. and Losson, B. (2004). Survival, immune responses and tissue cyst production in outbred 
(Swiss white) and inbred (CBA/Ca) strains of mice experimentally infected with Neospora caninum tachyzoites. Veterinary Research 35, 225-232.

Risco-Castillo, V., Fernandez-Garcia, A., Zaballos, A., Aguado-Martinez, A., Hemphill, A., RodriguezBertos, A., Alvarez-Garcia, G. and Ortega-Mora, L. M. (2007). Molecular characterisation of BSR4, a novel bradyzoite-specific gene from Neospora caninum. International Fournal for Parasitology 37, 887-896. doi: 10.1016/S0020-7519(07)00046-X.

Robinson, P. A., Anderton, B. H. and Loviny, T. L. (1988). Nitrocellulose-bound antigen repeatedly used for the affinity purification of specific polyclonal antibodies for screening DNA expression libraries. Fournal of Immunological Methods 108, 115-122.

Seeber, F. (1997). Consensus sequence of translational initiation sites from Toxoplasma gondii genes.

Parasitology Research 83, 309-311.
Vonlaufen, N., Guetg, N., Naguleswaran, A., Müller, N., Bjorkman, C., Schares, G., von Blumroeder, D., Ellis, J. and Hemphill, A. (2004). In vitro induction of Neospora caninum bradyzoites in vero cells reveals differential antigen expression, localization, and host-cell recognition of tachyzoites and bradyzoites. Infection and Immunity 72, 576-583.

Vonlaufen, N., Müller, N., Keller, N., Naguleswaran, A., Bohne, W., McAllister, M. M., Bjorkman, C., Müller, E., Caldelari, R. and Hemphill, A. (2002). Exogenous nitric oxide triggers Neospora caninum tachyzoite-to-bradyzoite stage conversion in murine epidermal keratinocyte cell cultures. International Fournal for Parasitology 32, 1253-1265.

Weiss, L. M., Ma, Y. F., Takvorian, P. M., Tanowitz, H. B. and Wittner, M. (1998). Bradyzoite development in Toxoplasma gondii and the hsp70 stress response. Infection and Immunity 66, 3295-3302. 